\section{In Vivo Difficulties}

SIR,-The use of the terms "in vitro" and "in vivo" is now deeply entrenched in the scientific literature. They are used to denote the difference between experiments performed outside the living organism (although often with living tissue, and those carried out inside the organism. The use of the two terms, although hallowed by time, sometimes causes difficulty, especially as editors of learned journals differ in the extent of their tolerance and degree of their pedanticism. Some editors are prepared to accept the terms virtually as the author proposes, irrespective of syntactical or scientific niceties. Some turn a blind eye to their suspiciously foreign sound and are prepared to admit them as current English usage. Others, more severe, by clapping the terms in italics, clearly still regard them as aliens against whom the innocent reader must be warned. Hyphens between the two parts of each term are not usually required, but on occasions have been insisted upon by the illiberal of outlook. Although strictly "in vitro" and "in vivo" are adverbial phrases (and are only so used by cognoscenti) they are now often misused as adjectives. Hence one reads of "in vitro experiments" and the even more disgraceful "in vitro results". Even "semi-in-vivo" (hyphenated surely) experiments have recently been threatened. Fowler, unfortunately, wrote before such indignities became common, and has nothing to say on the matter.

With due awareness of Lord Chesterfield's famous maxim, I should like to suggest the introduction of two new words to replace "in vitro" and "in vivo". These would be the simple adjectives "vitral" and "vival" respectively. The new words are short, their derivation is etymologically pure and their meaning by past association) is clear, when referring either to the tests themselves or to the results of tests. Moreover, they will never need italics or hyphens. Reference to various technical dictionaries has disclosed, perhaps surprisingly, no prior use of such adjectives. Although their introduction, it is realized, would not be so traumatic as the introduction of SI units, nor so subversive as the substitution of "retinol" for vitamin $\mathrm{A}^{\prime}$, there are bound to be views in favour of the status quo and it would be interesting to hear them.

Yours faithfully,

J. GREEN

19 Vineyard Hill Road, Wimbledon,

London SW19

\section{Billion Confusion}

SIR,-Teodor Juskiewicz (Nature, 228, $297 ; 1970)$ referred to the American practice of using the word "billion" to mean $10^{9}$ instead of $10^{12}$ and he appealed to American colleagues not to use the misleading term parts per billion.

I support Juskiewicz's appeal and suggest that it is time that some agreement was reached to avoid misunderstandings, which can arise by the use of this, at present, equivocal word.

To my mind the word "billion" means a million to the power of two, similarly "trillion" means a million to the power of three and so on using suitable prefixes added to the root "-illion" for numbers of the type $10^{6 n}$ (where $n$ is an integer).

There is some need for a simple name for the number $10^{9}$ which would be preferable to the rather clumsy "thousand million". The word "milliard", obviously familiar to Juskiewicz and, I understand, currently used in France, seems an obvious choice. Furthermore, this word could form the basis of a system of naming large numbers of the type $10\left({ }^{6 n+3}\right)$ in the same way that "million" has for the $10^{6 \mathrm{n}}$ numbers. Thus $10^{15}$ would be called a billiard and $10^{21}$ a trilliard, and so on.

Yours faithfully,

\section{R. M. BOROUGHS}

55 Wolsey Drive, Walton-on-Thames, Surrey

\section{Molecular Mass}

SIR,-Dr Edsall has explained (Nature, 228,888 ; 1970) the useful distinctions that should be preserved among the expressions, molecular mass, relative molecular mass (commonly called "molecular weight") and molar mass. These quantities have respective dimensions: mass, unity ("dimensionless") and mass $x$ (amount of substance $)^{-1}$. The common unit of molar mass (not its dimension) is the gram per mole (symbol, $\mathrm{g} / \mathrm{mol}$ or $\mathrm{g} \mathrm{mol}^{-1}$ ). Among recognized units of molecular mass is the unified atomic mass unit (symbol u), defined as the fraction $1 / 12$ of the mass of an atom of the nuclide ${ }^{12} \mathrm{C}\left(1 \mathrm{u}=1.66053 \times 10^{-27} \mathrm{~kg}\right.$ approximately), and for which Dr Edsall recommends the simpler name, dalton, widely used by biochemists. (His examples of different statements expressing the same fundamental facts should have read: "the molar mass of protein $\mathrm{X}$ is $25,000 \mathrm{~g}$ mol-1", "the molecular mass of protein $\mathrm{X}$ is 25,000 daltons", and "the relative molecular mass (that is, molecular weight) of protein $X$ is 25,000 ".)

The 14th General Conference of Weights and Measures (CGPM) of the International Bureau of Weights and Measures, convening in 1971, will consider a recommendation approved in 1969 by the International Committee on Weights and Measures (CIPM) to include the mole as a base unit of the International System of Units (SI), besides the six base units on which the system was established in 1960 (the metre, the kilogram, the second, the ampere, the kelvin, and the candela). The additional base unit is needed to introduce SI units for the "molar" physical quantities (molar volume, molar mass, molar heat capacities, molar enthalpy of formation, etc.). The appropriate physical quantity corresponding to the concept that different substances have natural molecular constitutions (the word "molecular" here being used in a broad sense to include any specified constituent entities, whether they be molecules, atoms, ions, ion pairs, or other aggregates) has not until recently been identified by a commonly recognized name. The name, "amount of substance", has now been adopted by the International Union of Pure and Applied Chemistry, the International Union of Pure and Applied Physics, and the International Organization for Standardization to define a physical quantity proportional to the number of constituent entities of that substance (molecules or other entities, such as may be specified by a chemical formula). The proportionality factor is the same for all substances and may be taken to be the reciprocal of the Avogadro constant. A unit for the physical quantity, the mole, has long been recognized. The definition given by the CIPM in 1967, confirmed in 1969, and included in the draft proposal prepared for the 14th CGPM introducing the mole as a base unit in the SI, is as follows ${ }^{1}$ :

The mol is the amount of substance of a system which contains as many elementary entities as there are atoms in $\mathbf{0 . 0 1 2}$ kilogram of carbon 12 .

Note: When the mol is used, the elementary entities must be specified and may be atoms, molecules, ions, electrons, other particles, or specified groups of such particles.

If the 14th CGPM accepts the mole so defined as an SI base unit, then the SI unit of molar mass will be the kilogram per mole $\left(\mathrm{kg} \mathrm{mol}^{-1}\right)$. This unit is large for ordinary chemical purposes and the common unit, gram per mole $\left(1 \mathrm{~g} \mathrm{~mol}^{-1}\right.$ 
$=10^{-3} \mathrm{~kg} \mathrm{~mol}^{-1}$ ), will continue in use as an accepted decimal sub-multiple of the SI unit. However, the SI unit itself is suitable for expressing values of the molar mass for macromolecular substances. Thus, one could add to Dr Edsall's equivalent statements the alternative : "the molar mass of protein $\mathrm{X}$ is $25 \mathrm{~kg}$ $\mathrm{mol}^{-1}$ ".

Although the unit of mass, "unified atomic mass unit", is outside the SI, it has been recognized by the CIPM as useful in specialized fields of scientific research $^{1}$. Its value expressed in the SI unit, the kilogram, is derived by experiment and is therefore not known exactly. Although in general one should be chary of proliferating special names, the present name for this unit, even when contracted to "atomic mass unit" (the term "unified" distinguishing it from slightly different earlier units based on ${ }^{16} \mathrm{O}$ and on $\mathrm{O}=16$ ), is not notably convenient or informative. Dr Edsall's suggestion that it be renamed the dalton merits consideration by the international agencies concerned with standardization of chemical and physical nomenclature so long as the unit itself continues to be recognized by the CIPM as one of those useful outside the SI in specialized fields. It would not be helpful if scientists in different fields employed different names for the same unit.

Yours faithfully,

\section{Martin A. Paul}

Division of Chemistry and

Chemical Technology,

National Academy of Sciences-

National Research Council,

Washington, DC 20418, USA

1 The International System of Units (SI), translation approved by the International Bureau of Weights and Measures of its publication, Le Système International d'Unités, prepared jointly and published independently by the National Physical Laboratory, UK, and the National Bureau of Standards, USA: National Bureau of Standards Special Publication 330, 1970 , US Government Printing Office, Washington, DC 20402

\section{Definition of Intelligence}

SIR,-Because others (Nature, 228, 1008 ; 1970) have commented on the definition of intelligence put forward by Fatmi and Young (Nature, 228, 97; 1970) and subsequently extended by myself (Nature, 228, 589; 1970), I would like to make some further observations.

With regard to the letter from $\mathbf{P}$. $\mathbf{M}$. Muller, the process of induction would be covered by my own definition, as would "synthetic a priori". However, processes of reasoning from the part to the whole, from the particular to the general, and from the individual to the universal, are not identical and isomorphic processes, nor are they symmetrical with respect to deduction and induction.

If we accept Gödel's theorem, a single, finite automaton with a phrase-structure grammar can be either complete and consistent (closed) or universal (open). A Gödel complete system will accept only tautologies or empirically verifiable sensedata that have been specified in the instruction set, rejecting all other inputs as illogicality or "noise". The possibility of new or unspecified states is excluded. If we assume that human intelligence not only construes syllogisms, but also discovers, elucidates and initiates the previously unknown, then it is clear that this cannot be a property of Gödel complete automata (existing computers). Indeed, it would seem that an incomplete instruction set (a quasi-nondeterministic system) is a necessary condition for the emergence and evolution of intelligence, as we observe it in living systems. However, the possibilities of machines do not end with single finitestate machines or with phrase-structure grammars.

In my own work I have been considering the possibilities of hierarchical networks of automata, some of them backward deterministic ${ }^{1}$, in an attempt to solve the Gödel theorem problem for quasi-non-deterministic systems, including brain-models. The basic idea is to axiomatize the levels of the system independently and use negative feedback to control the universality (requisite variety) of both individual levels and the system as a whole. An essential part of the control system is an order : disorder detector, as suggested by $\mathbf{H}$. B. Barlow in his letter. This type of system would also imply that the original definition of Fatmi and Young would be too broad to draw a valid distinction between men and machines.

With regard to the letter from $\mathrm{H}$. A. Cook. Any system is quantifiable if one knows what to measure and how to measure it. It is another matter to decide whether such a quantification provides an adequate description of the system as a whole. The informationtheoretic brain model mentioned above implies a physiological symbol-processing mechanism in the brain, which could form a substrate for the heritable components of both intelligence and linguistic behaviour. Since such a component would be determined by input-rate and digitspan, and would be invariant with respect to learning, it should be possible to isolate and quantify it given a calibrated digital input and criteria for assessing the output response in quantitative terms. With regard to a quantified definition of intelligence, without recourse to linguistic behaviour, we may be up against a special case of Richard's paradox.

The correspondence following Fatmi and Young's original letter has emphasized the need for further dialogue concerning the theoretical and philosophical aspects of machine and human intelligence, and it is gratifying to learn that the Cambridge Branch of the Brain Research Association is setting up a forum in this area of study.

Yours faithfully, GORDON HYDE

11 The Close,

Dunmow, Essex CM6 1 EW

1 Wang How, A Survey of Mathematical Logic, 175 (North-Holland, 1964).

\section{Obituary}

\section{Dr J. E. Falk}

JoHN EDwIN FALK, chief of the division of plant industry, Commonwealth Scientific and Industrial Research Organization, Canberra, died on October 25, 1970. Born in 1917 at Cessnock, NSW, he studied pharmacy at the University of Sydney, but finding that his interests lay in chemistry he completed a Bachelor of Science degree in 1942. After graduating he joined Professor V. M. Trikojus in an investigation of synthetic methods of preparation of essential drugs unavailable in war time Australia. In 1944 he became Chief Chemist at Bayer's in Sydney and at the end of the war returned to research in the university on a Wellcome fellowship under Professor Adrian Albert. During this period his research into the mode of action of certain antimalarial drugs awakened his interest in biochemistry and led him into the field of haem pigments. In 1947 he was awarded a grant by the National Health and Medical Research Council to work at the Royal North Shore Hospital, Sydney, under Professor M. R. Lemberg, FRS. Here he investigated the prosthetic group of cytochrome oxidase and learnt a great deal about porphyrins.

In 1948, Falk was granted a Nuffield travelling fellowship and with financial assistance from the National Health and Medical Research Council he went to University College Hospital Medical School in London to work with Professor C. Rimington, FRS. His research included a systematic study of the infrared spectra of porphyrins and haems as well as further work on cytochrome oxidase. He received his $\mathrm{PhD}$ in 1951. A "Nuffield Unit of Pyrrole Pigment Research" was established in Professor Rimington's department and Falk was appointed director. In 1953, he was awarded a Foulerton research fellowship by the Royal Society. During this period, he developed analytical methods for porphyrins and turned his attention 